\title{
Oxcarbazepine: a new drug in the management of intractable trigeminal neuralgia
}

\author{
J M ZAKRZEWSKA, P N PATSALOS \\ From the Department of Oral Medicine, Institute of Dental Surgery, Eastman Dental Hospital, London, INSEC \\ (Institute of Neurology, National Hospital for Nervous Diseases, and National Society for Epilepsy Research \\ Group, Queen Square) London, and Chalfont Centre for Epilepsy, Buckinghamshire, UK
}

SUMMARY The efficacy and tolerability of oxcarbazepine, a keto derivative of carbamazepine, has been assessed in six patients (two males, four females; mean age 61 years, range 42-77), with trigeminal neuralgia refractory to carbamazepine therapy, over a period of 6 months. An excellent therapeutic response to oxcarbazepine was seen in all patients with pain control correlating well with serum drug concentrations of oxcarbazepine and its primary active metabolite 10-OH-carbazepine. Onset of the effect was observed within 24 hours in all cases. An overall serum therapeutic concentration range, in the six patients, of 50-110 $\mu \mathrm{mol} / 1$ of $10-\mathrm{OH}$-carbazepine corresponding to a daily effective dose range of $1200-2400 \mathrm{mg}(14.6-35.6 \mathrm{mg} / \mathrm{kg}$ body weight) oxcarbazepine, was observed. There was a significant correlation between oxcarbazepine dose and serum oxcarbazepine $(\mathrm{r}=0.695, \mathrm{p}<0.05)$ and 10-OH-carbazepine $(\mathrm{r}=0.957, \mathrm{p}<0.001)$ concentrations. Oxcarbazepine was well tolerated and no significant side effects were identified, though a mild hyponatraemia was observed during high doses ( $>28$ and $>35 \mathrm{mg} / \mathrm{kg} /$ day) in two patients. It is concluded that oxcarbazepine has potent antineuralgic properties in the absence of significant side effects and therefore may be useful in the management of intractable trigeminal neuralgia.

Carbamazepine is currently the drug of choice in the management of trigeminal neuralgia with an onset of action within 24 hours. $^{1-4}$ It is efficacious in only 70 $80 \%$ of patients, and can be associated with toxicity manifested by drowsiness, confusion, nausea, ataxia, nystagmus and hypersensitivity necessitating discontinuation of medication. ${ }^{56}$ Twenty per cent of patients responding initially to treatment may subsequently become refractory to carbamazepine. ${ }^{7}$

Oxcarbazepine (10,11-dihydro-10-oxo-5H-dibenz(b,f)azepine-5-carboxamide), a keto derivative of carbamazepine, has been shown to have equal efficacy to carbamazepine in the management of epilepsy but with less side effects and greater tolerance. ${ }^{8-10}$ Oxcarbazepine is rapidly absorbed after oral ingestion $^{1112}$ and is metabolised to two major metabolites, 10,11-dihydro-10-hydroxycarbamazepine (10-OH-carbazepine) and trans-10, 11-dihydro-10, 11-dihydroxy-

\footnotetext{
Address for reprint requests: Dr P N Patsalos, Department of Chemical Pathology, The National Hospital for Nervous Diseases, Queen Square, London WCIN 3BG, UK.
}

Received 14 June 1988 and in revised form 24 September 1988. Accepted 8 November 1988 carbamazepine. 10-OH-carbazepine is the primary metabolite and is active pharmacologically as an anticonvulsant drug. ${ }^{13}$ Additionally, oxcarbazepine has been found useful in the management of affective disorders ${ }^{14}$ and spasticity. ${ }^{15}$ Recently, Farago $(1987)^{16}$ in a series of 13 patients with trigeminal neuralgia has reported that oxcarbazepine has antineuralgic properties in the absence of significant side effects.

The present evaluation was designed to assess the efficacy and tolerability of oxcarbazepine in the management of trigeminal neuralgia in 6 patients refractory to carbamazepine therapy over a period of 6 months and to determine systematically individual therapeutic doses of oxcarbazepine and therapeutic serum concentration ranges for 10-OH-carbazepine, the primary active metabolite of oxcarbazepine.

\section{Patients and methods}

All six patients had classical idiopathic trigeminal neuralgia as indicated by the following criteria: (1) pain in the distribution of the trigeminal nerve; (2) pain of "electric shock", shooting or stabbing character of short duration; (3) pain provoked by innocuous stimuli such as light touch or vibration; (4) paroxysmal pain with episodes of complete 
remission; (5) complete abolition of pain could be achieved by a local anaesthetic injection into the trigger zone or by a regional block.

The six patients (four females and two males) aged 42-77 years (mean 61) had been diagnosed as having trigeminal neuralgia for 6 months to 16 years (mean 7.4). Details of the individual patients and their medication regimens just prior to oxcarbazepine treatment are shown in table 1. Two patients had a proven allergy to carbamazepine ${ }^{5}$ and four patients had failed to gain pain control with carbamazepine or phenytoin due to the development of side effects.

At the time of entry into the assessment all patients had been suffering from painful paroxysms for at least 4 weeks. Each patient had a history of good drug compliance and was capable of assessing the severity of his/her pain. Informed written consent was obtained from all patients and oxcarbazepine was prescribed on a named patient basis. Patients were free to withdraw from the assessment at any time.

\section{Assessment protocol design}

Patients were clinically evaluated as out-patients and oxcarbazepine administered orally in the form of $300 \mathrm{mg}$ tablets 24 times a day (Ciba Geigy Pharmaceuticals, UK). Prior medication was either withdrawn immediately (2 patients) or withdrawn over a period of 2 days ( 4 patients). Patients were examined weekly and oxcarbazepine adjusted until pain control was achieved, and then followed up at 2-4 weekly intervals. At the end of a pain free 2-week period, patients were considered optimumly managed on oxcarbazepine and dosage decreased by one dose/week $(300 \mathrm{mg})$. If patients relapsed dosage was re-titrated. In four patients depression and anxiety was assessed by the use of the Hospital Anxiety and Depression Scale ${ }^{17}$ before the start of oxcarbazepine and after 6 months of treatment.

Biochemical and haematological screens were carried out prior to treatment with oxcarbazepine and at intervals during the assessment period. Blood samples for the determination of steady state serum oxcarbazepine and 10-OH-carbazepine concentrations were collected between 3 and 4 hours after the morning dose. Serum samples were stored frozen at $-20^{\circ} \mathrm{C}$ until analysis.

\section{Pain registration}

All patients kept a weekly pain and activity diary where selfregistration of pain was recorded. The diary was divided into 3 hour periods for the recording of diurnal pain severity and drug related side effects. This type of pain assessment in trigeminal neuralgia has been used previously with success ${ }^{18}$ and allows for the rapid establishment of dose and serum drug concentration/response correlates. The severity of the pain paroxysm was assessed as nil -0 , mild -1 , moderate2 , severe- 3 , most severe -4 .

\section{Analysis of oxcarbazepine and 10-OH-carbazepine}

Oxcarbazepine and its primary metabolite 10-OH-carbazepine were analysed by a recently developed microassay technique using high pressure liquid chromatography. ${ }^{19}$ Briefly, to $300 \mu \mathrm{l}$ of serum was added $4 \mu \mathrm{g}$ of 10 -methoxycarbamazepine as internal standard, $300 \mu \mathrm{l}$ of $0.2 \mathrm{M} \mathrm{NaOH}$ and $1 \mathrm{ml}$ dichloromethane. After shaking for $15 \mathrm{~min}$ and centrifuging for a further $5 \mathrm{~min}$, the aqueous layer was aspirated and the dichloromethane layer transferred to a clean $2.0 \mathrm{ml}$ microcentrifuge tube (Sarstedt Ltd) and evaporated to dryness using oxygen free nitrogen. Each sample was then reconstituted in $15 \mu \mathrm{l}$ acetonitrile and $10 \mu \mathrm{l}$ injected into a Spectra Physics SP8000 liquid chromatograph. LiChrosorb RP8 $10 \mu$ column (Hichrom Ltd) and an acetonitrile:water (35:65) mobile phase (flow rate $1.8 \mathrm{ml} / \mathrm{min}$ ) resulted in retention times for $10-\mathrm{OH}$-carbazepine, oxcarbazepine and 10-methoxycarbamazepine of $3.5,5.0$ and $8.5 \mathrm{~min}$, respectively. The Schoeffel S $770 \mathrm{UV}$ detector was set at $215 \mathrm{~nm}$.

\section{Results}

Oxcarbazepine dosage ranged from $600 \mathrm{mg}$ to 2400 $\mathrm{mg} /$ day. Steady state serum oxcarbazepine and 10 $\mathrm{OH}$-carbazepine concentrations at 3-4 hours after the morning dose ranged from 0.0-11.4 $\mu \mathrm{mol} / 1$ and 42 $150 \mu \mathrm{mol} / \mathrm{l}$ respectively. Both oxcarbazepine and 10 $\mathrm{OH}$-carbazepine serum concentrations correlated significantly, $r=0.957(\mathrm{p}<0.001)$ and $\mathrm{r}=0.695(\mathrm{p}<$

Table 1 Clinical evaluation of the six patients with trigeminal neuralgia

\begin{tabular}{|c|c|c|c|c|c|c|c|c|}
\hline Patient & Sex & $\begin{array}{l}\text { Age } \\
(y r)\end{array}$ & $\begin{array}{l}\text { Duration of } \\
\text { trigeminal } \\
\text { neuralgia }(y r)\end{array}$ & $\begin{array}{l}\text { Location of } \\
\text { neuralgia }\end{array}$ & $\begin{array}{l}\text { Medication just prior } \\
\text { to oxcarbazepine } \\
\text { (dose, } \mathrm{mg} / \mathrm{d} \text { ) }\end{array}$ & $\begin{array}{l}\text { Duration of } \\
\text { last treatment } \\
\text { therapy (mths) }\end{array}$ & $\begin{array}{l}\text { Steady state } \\
\text { serum concen- } \\
\text { tration }(\mu \mathrm{mol} / \mathrm{l})\end{array}$ & $\begin{array}{l}\text { Reason for } \\
\text { initiation of } \\
\text { oxcarbazepine }\end{array}$ \\
\hline 1 & $\mathbf{M}$ & 77 & 3.0 & $\mathbf{L}-\mathbf{V}_{\mathrm{b}}$ & Phenytoin (300) & 3.0 & - & \multirow{6}{*}{$\begin{array}{l}\text { Refractory to management } \\
\text { with phenytoin. Hypersen- } \\
\text { sitized to carbamazepine } \\
\text { Phenytoin induced side } \\
\text { effect eg drowsiness. Hyper- } \\
\text { sentized to carbamazepine } \\
\text { Suffered nausea and head- } \\
\text { aches. Low white cell count } \\
\text { Refractory to treatment. } \\
\text { Nausea and drowsiness } \\
\text { Refractory to treatment. } \\
\text { Nausea and drowsiness } \\
\text { Refractory to treatment. } \\
\text { Nausea and drowsiness }\end{array}$} \\
\hline 2 & $\mathbf{F}$ & 42 & 5.0 & $\mathbf{R}-\mathbf{V}_{\mathrm{b}}$ & Phenytoin $(600)$ & $2 \cdot 0$ & 119 & \\
\hline 3 & $\mathbf{F}$ & 72 & $10 \cdot 0$ & $\begin{array}{l}R-V_{b} \\
R-V^{\prime}\end{array}$ & $\begin{array}{l}\text { Phenytoin (300) } \\
\text { Carbamazepine (400) }\end{array}$ & 1.0 & $\begin{array}{l}36 \\
13\end{array}$ & \\
\hline 4 & $\mathbf{F}$ & 58 & 0.5 & $\mathbf{L}-\mathbf{V}_{\mathrm{c}}^{\mathrm{c}}$ & $\begin{array}{l}\text { Phenytoin (300) } \\
\text { Carbamazepine (600) }\end{array}$ & $5 \cdot 0$ & $\begin{array}{l}44 \\
21\end{array}$ & \\
\hline 5 & $\mathbf{M}$ & 69 & $16 \cdot 0$ & $\begin{array}{l}\mathbf{R}-\mathbf{V}_{\mathbf{a}} \\
\mathbf{R}-\mathbf{V}_{\mathbf{m}}\end{array}$ & Carbamazepine (800) & $8 \cdot 0$ & 47 & \\
\hline 6 & $\mathbf{F}$ & 47 & $10 \cdot 0$ & $\mathbf{R}-\mathbf{V}_{\mathrm{c}}^{\mathrm{b}}$ & $\begin{array}{l}\text { Phenytoin (300) } \\
\text { Carbamazepine (1600) }\end{array}$ & $8 \cdot 0$ & $\begin{array}{l}36 \\
34\end{array}$ & \\
\hline
\end{tabular}

$\mathrm{L}=$ left, $\mathrm{R}=$ right, $\mathrm{V}_{\mathrm{a}}=$ Ophthalmic division trigeminal nerve, $\mathrm{V}_{\mathrm{b}}=$ Maxillary division trigeminal nerve, $\mathrm{V}_{\mathrm{c}}=$ Mandibular division trigeminal nerve. 


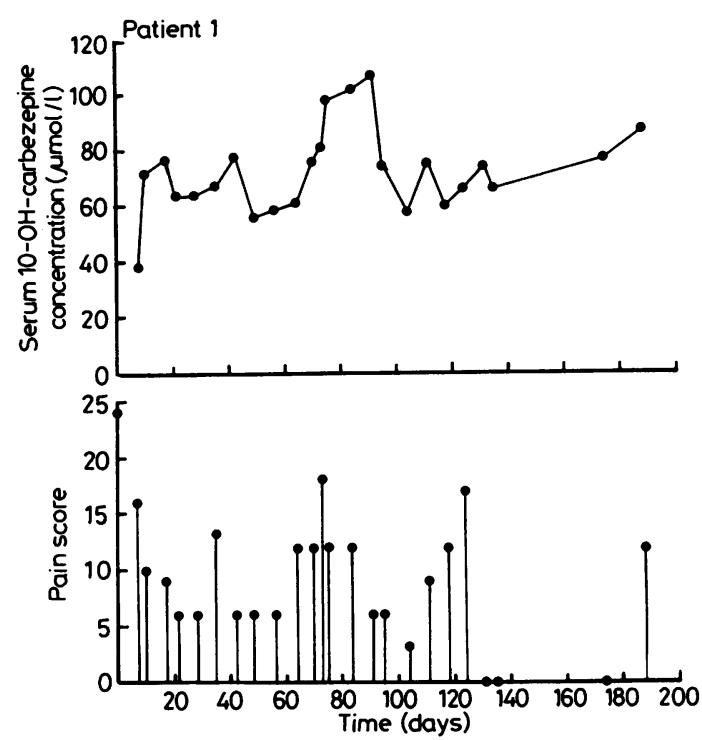

Fig 1 Steady state serum 10-OH-carbazepine concentrations (upper panel) and corresponding daily pain scores (lower panel) during 6 months of oxcarbazepine treatment (patient 1).

$0.05)$ respectively, with oxcarbazepine dose. Additionally, serum concentrations of oxcarbazepine, which were 15-30 fold lower than those of $10-\mathrm{OH}$-carbazepine, and 10-OH-carbazepine correlated significantly $(\mathrm{r}=0.810, \mathrm{p}<0.001)$.

A longitudinal comparison of total daily pain score and serum 10-OH-carbazepine concentrations in two

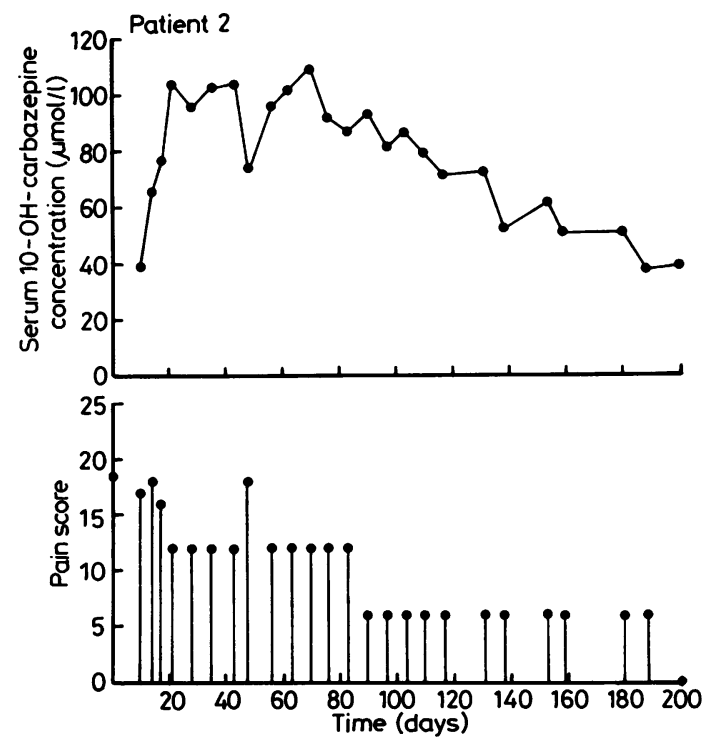

Fig 2 Drug concentrations and pain scores in patient 2. patients during 6 months of oxcarbazepine therapy is shown in figs 1 and 2. For clarity and because serum oxcarbazepine was not detectable at the lower oxcarbazepine doses, serum oxcarbazepine concentrations have been omitted from the figures. The daily pain scores shown (maximum score $=24$ ) are those of the 24 hour period prior to the morning serum $10-\mathrm{OH}$ carbazepine concentration. There was a wide interindividual range both prior to oxcarbazepine treatment (day 0) and during the six month assessment period and this is a reflection to some extent, of the clinical condition with spontaneous fluctuations in the severity of the pain. Additional variation can probably be attributed to inter-individual differences in pain estimation, consequently each patient acted as his/her own control. Pain scores of 7 and above were associated with a decline in ability to eat and talk.

The response to oxcarbazepine treatment was dramatic in all patients with the onset of effect occurring in all cases within 24 hours. This is particularly well illustrated by patient 2 (fig 2 ) who had been unable to maintain good oral hygiene prior to commencement of oxcarbazepine therapy (fig 3). 10$\mathrm{OH}$-carbazepine concentration ranges were determined for each patient and these data are shown in table 2. Pain control correlated well with serum 10$\mathrm{OH}$-carbazepine concentration with excellent overall pain alleviation in our 6 patients when serum 10-OHcarbazepine concentrations were in the range 50-110 $\mu \mathrm{mol} / \mathrm{l}$. Large changes in serum 10-OH-carbazepine concenrations were associated with pronounced and almost immediate alteration in pain score (for example fig 2, day 49). Anxiety and depression scores in three of the four patients assessed were reduced by an average of $43 \%$ and $59 \%$ respectively. The continuing depression seen in the fourth patient can be attributed to a cardiac condition and his anaesthesia dolorosa.

No clinical side effects were observed although a mild hyponatraemia $(\mathrm{Na}=123-131 \mathrm{mmol} / \mathrm{l})$ was seen in two patients taking high doses $(>28 \mathrm{mg} / \mathrm{kg} / \mathrm{d}$ and $>35 \mathrm{mg} / \mathrm{kg} / \mathrm{d}$ ) of oxcarbazepine. One of these patients had an associated $1 \mathrm{~kg}$ weight gain. All other haematological and biochemical parameters were normal.

\section{Discussion}

Oxcarbazepine has been used to treat systematically six patients with intractable trigeminal neuralgia over a period of 6 months and good therapeutic responses have been observed. The associated reduction in the anxiety and depression score in three of the four patients tested, reflected the very clear improvement in the patients' quality of life.

Since oxcarbazepine is rapidly metabolised to 10 $\mathrm{OH}$-carbazepine it is difficult to ascertain which 


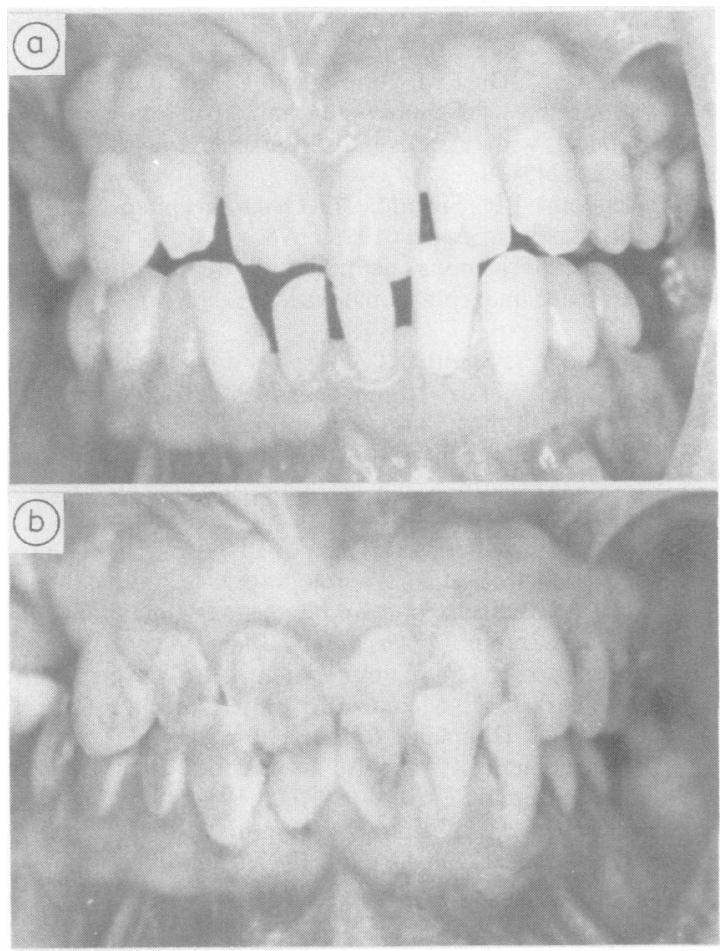

Fig 3 Oral hygiene before (a) and 2 months after (b) treatment with oxcarbazepine (patient 2). The maintenance of good oral hygiene after oxcarbazepine treatment is clearly visible.

compound is responsible for the observed effects in our patients. Farago ${ }^{16}$ has, however, administered 10$\mathrm{OH}$-carbazepine to 11 patients with trigeminal neuralgia who responded very well and suggests that perhaps oxcarbazepine's therapeutic role may be that of a prodrug. The significant correlation between dose and serum concentrations of oxcarbazepine and $10-\mathrm{OH}-$ carbazepine is in agreement with Farago $^{16}$ and suggests that first order kinetics operate at serum concen-

Table 2 Oxcarbazepine therapeutic dose and serum 10-OHcarbazepine ranges in six patients

\begin{tabular}{llll}
\hline & $\begin{array}{l}\text { Dose needed to achieve } \\
\text { optimal pain control }\end{array}$ & $\begin{array}{l}\text { Serum } \\
\text { 10-OH-carbazepine } \\
\text { therapeutic range } \\
\mu m o l / l\end{array}$ \\
\cline { 2 - 4 } Patient & $m g / d$ & $m g / k g / d$ & $70-80$ \\
\hline 1 & 1200 & $14 \cdot 6$ & $90-110$ \\
2 & 2400 & $21 \cdot 3$ & $60-80$ \\
3 & 1200 & $21 \cdot 0$ & $60-80$ \\
4 & 2100 & $32 \cdot 8$ & $50-70$ \\
5 & 1500 & $18 \cdot 0$ & $70-90$ \\
6 & 2100 & $35 \cdot 6$ & \\
Overall & & & $50-110$ \\
patient & $1200-2400$ & $14 \cdot 6-35 \cdot 6$ & \\
range: & & & \\
\hline
\end{tabular}

trations observed in this assessment $(<152 \mu \mathrm{mol} / 1,10-$ $\mathrm{OH}$-carbazepine; $<22.5 \mu \mathrm{mol} / 1$ oxcarbazepine).

A placebo effect in trigeminal neuralgia is negligible, ${ }^{3}$ therefore the significant correlation between serum oxcarbazepine and 10-OH-carbazepine concentrations and pain control suggests that the measurement of either would be a good index of therapeutic efficacy. However, the fact that serum 10$\mathrm{OH}$-carbazepine concentrations are 15-30 fold higher than that of oxcarbazepine, and that pharmacologically $10-\mathrm{OH}$-carbazepine may be more important, indicates that the measurement of serum $10-\mathrm{OH}$ carbazepine is perhaps more appropriate.

The optimal serum therapeutic range, in our patients, for 10-OH-carbazepine was $50-110 \mu \mathrm{mol} / \mathrm{l}$ and compares well with that previously reported (35$100 \mu \mathrm{mol} / \mathrm{l}) .{ }^{16}$ No adverse side effects were reported by our patients and the allergic skin reaction, present in two patients which were hypersensitive to carbamazepine, completely cleared during oxcarbazepine therapy. The hyponatraemia that has been associated with oxcarbazepine therapy ${ }^{2021}$ was only observed at the high doses $(>28$ and $>35 \mathrm{mg} / \mathrm{kg} /$ day in two different patients), was mild and essentially clinically asymptomatic.

It is concluded from the present study that oxcarbazepine has potent antineuralgic properties in the absence of significant side effects and therefore may be useful in the management of intractable trigeminal neuralgia.

We are grateful to Dr F F Nally and Mr D G T Thomas for referring their patients. We thank Ms $J$ Wilson and Mr A A Elyas for technical assistance, Mrs Marina Shaw for her excellent secretarial assistance and Ciba Geigy Pharmaceuticals (UK) for the supply of oxcarbazepine. Generous financial support from the Welton Foundation to JMZ and CSO Valuations to PNP is gratefully acknowledged.

\section{References}

1 Campbell FG, Graham JG, Zilkha KJ. Clinical trial of carbamazepine (Tegretol) in trigeminal neuralgia. $J$ Neurol Neurosurg Psychiatry 1966;29:265-7.

2 Rassmusen P, Rushede J. Facial pain treated with carbamazepine (Tegretol). Acta Neurol Scand 1970; 46:385-408.

3 Rockliff BW, Davies EH. Controlled sequential trials of carbamazepine in trigeminal neuralgia. Arch Neurol 1966;15:129-36.

4 Tomson T, Tybring G, Bertilsson L, Ekbom K, Rane A. Carbamazepine therapy in trigeminal neuralgia. Clinical effects in relation to plasma concentration. Arch Neurol 1980;37:699-703.

5 Zakrzewska JM, Ivanyi L. In vitro lymphocyte proliferation by carbamazepine, carbamazepine-10, 11 -epoxide and oxcarbazepine in the diagnosis of drug induced 
hypersensitivity. J Allergy Clin Immun 1988;82:110-5.

6 Sillanpaa M. Carbamazepine pharmacology and clinical use. Acta Neurol Scand 1981;64(suppl 88):115-6.

7 Taylor JC, Brauer S, Espir MLE. Long term treatment of trigeminal neuralgia with carbamazepine. Postgrad Med J 1981;57:16-8.

8 Rai PV. Clinical trial for the estimation of anticonvulsant properties and side reactions of a new drug ketocarbamazepine. In: Wada JA, Penry JK, eds. Advances in Epileptology: Xth Epilepsy International Symposium. New York: Raven Press, 1980:357.

9 Philbert A, Dam M, Jackobsen K. Oxcarbazepine in the treatment of epilepsy-a usable alternative to carbamazepine? Irish J Med Sci 1986;155:297.

10 Reinikainen KJ, Keranen T, Halonen T, Komulainen H, Riekkinen PJ. Comparison of oxcarbazepine and carbamazepine: a double blind study. Epilepsy Res 1987;1:284-9.

11 Schutz H, Feldman KF, Faigle JW, Kriemler HP, Winkler $\mathrm{T}$. The metabolism of ${ }^{14} \mathrm{C}$-oxcarbazepine in man. Xenobiotica 1986;16:769-78.

12 Theisohn M, Heimann G. Disposition of the antiepileptic oxcarbazepine and its metabolites in healthy volunteers. Eur J Pharmacol 1982;22:545-51.

13 Baltzer V, Schmutz M. Experimental anticonvulsive properties of GP 47680 and GP 47779, its main human metabolite; compounds related to carbamazepine. In: Meinardi H, Rowan AJ, eds. Advances in Epileptology.
Amsterdam and Lisse: Swetz and Zeitlinger, 1977: 295-9.

14 Emrich HM, Dose M, von Zerssen D. The use of sodium valporate, carbamazepine and oxcarbazepine in patients with affective disorders. $J$ Affective Disord 1985;8:243-50.

15 Bittencourt PR, Silvado CE. Oxcarbazepine, GP 4779 and spasticity. Lancet 1985;i:676.

16 Farago F. Trigeminal neuralgia: its treatment with two new carbamazepine analogues. Eur Neurol 1987;26: 73-83.

17 Zigmond AS, Snaith RP. Hospital anxiety and depression scale. Acta Psychiatr Scand 1983;67:361-70.

18 Tomson T, Tybring G, Bertilsson L, Ekbon K, Rane A. Carbamazepine therapy in trigeminal neuralgia: clinical effects in relation to plasma concentration. Arch Neurol 1980;37:699-703.

19 Elyas AA, Goldberg VD, Patsalos PN. A microanalytical high pressure liquid chromatographic technique for the assay of oxcarbazepine and its primary metabolite 10OH-carbazepine. J Chromatogr 1988; (in press).

20 Houtkooper MA, Lammertsma A, Meyer JWA, Goedhart DM, Meinardi $\mathrm{H}$, van Oorschot CEAH, Blom GF, Hoppener RJEA, Hulsman JARJ. Oxcarbamazepine (GP 47.680): a possible alternative to carbamazepine. Epilepsia 1987;28:693-8.

21 Johannessen AC, Nielsen OA. Hyponatremia induced by oxcarbazepine. Epilepsy Res 1987;1:155-6. 